\section{Pathological and electron microscopic studies on cold water disease among cultured rainbow trout (Oncorhynchus Mykiss Walbaum)}

\author{
Salah Mesalhy Aly, ${ }^{1}$ Wael G. Nouh, ${ }^{2,3}$ \\ Nashwa Abdel Atti,4 \\ Ahmed M. El-Ashram 5 \\ 1Pathology Department, Faculty \\ of Veterinary Medicine, Suez Canal \\ Universities, Ismailia, Egypt; 2Pathology \\ Department, Faculty of Veterinary \\ Medicine, Zagazig University, Zagazig, \\ Egypt; ${ }^{3}$ Department of Medical \\ Laboratories, Faculty of Community, \\ El-Namas, King Khaled University, Abha, \\ Saudi Arabia; ${ }^{4}$ Animal Health Research \\ Institite, Dokki, Gizza, Egypt; ${ }^{5}$ Central \\ Lab for Aquaculture Research, Abbassa, \\ Sharkia, Egypt
}

\section{Abstract}

The present study aims to investigate the etiology and pathogenesis of cold water disease among cultured rainbow trout (Oncorhynchus Mykiss Walbaum) reared at low water temperature on a private farm, and propose preventive and control measures to prevent the recurrence of the disease and its spread to the neighboring farms or to other countries. The disease is caused by Flavobacterium psychrophilum and is characterized clinically by high mortality rates (25\%) with necrotizing skin and fin lesions. Septicemia with muscular and gill involvement is observed in severely affected cases. The histopathological and ultrastructure alterations in the infected trout explain the pathogencity of this microorganism in many organs other than skin and fins either directly by these bacteria or by its extracellular products, or indirectly via the hypoxia and ion imbalance that results from skin and gill damage. Although some antibiotics, such as trimethoprime, chloramin $\mathrm{T}$ and oxytetracycline, are effective on the causative agent, improvement in water quality, vaccination, increasing fish resistance and strict hygiene as well as quarantine measures would all help.

\section{Introduction}

Fish diseases are extremely important with the rapid expansion in the aquaculture industry. Until recently, approximately $15-20$ bacte- ria species were known to be pathogenic for fish, whereas today approximately 70 species of bacteria have been identified from naturally infected fish. ${ }^{1}$

Bacterial cold water disease or peduncle disease of fish is common at relatively low water temperature. It is associated with necrotic skin and fin lesions..$^{2-5}$ This is well recognized in the United States. ${ }^{6}$ It induces systemic infection in rainbow trout fry and causes significant mortality in salmonid fry in Europe.7-10 Flexibacter pschrophila induces cold water disease and various other disease entities in salmonids, and necrotic skin and fin lesions caused by multifactorial agents.

Modern aquaculture practices involve significant domestic and international movement of live aquatic animals and animal products that facilitate the movement and spread of associated pathogens. The introduction of pathogens not only caused losses and mortalities in commercial systems, but also affects the human activities with a negative impact on rural, small-scale aquaculture and fisheries.

The present study aims to investigate the etiology of necrotic skin and fin lesions among cultured rainbow trout and their associated pathology together with development of some control measures.

\section{Materials and Methods}

\section{Signs and sampling}

Necrotic skin and fin lesions appear on rainbow trout with average body weight of $5 \mathrm{gm}$ with water temperature ranging between 10 $13^{\circ} \mathrm{C}$ and has a mortality rate of $25 \%$. Samples have been taken from fish; food and water for bacteriological examination and tissue specimens from infected fish are used for light and electron microscopic examinations. Medical and supportive treatment is given after the application of a sensitivity test.

\section{Isolation of Flavobacterium psychrophilum}

Tissue samples from spleen, kidney, skin lesion (if present) and skin mucus of all examined rainbow trout have been inoculated on TYES $(0.4 \%$ tryptone, $0.05 \%$ yeast extract, $0.05 \% \mathrm{MgSO}_{4} \times 7 \mathrm{H}_{2} \mathrm{O}, 0.05 \% \mathrm{CaCl}_{2} \times 2 \mathrm{H}_{2} \mathrm{O}, \mathrm{pH}$ 7.2) agar plates (1.5\%) as described by Holt $e t$ al. ${ }^{6}$ Plates are incubated at $15^{\circ} \mathrm{C}$ for seven days.

\section{Identification of Flavobacterium psychrophilum}

Bacteria forming yellow colonies typical for F. psychrophilum on TYES agar plates are identified using an esculin tube test.11 The ability of an isolate to degrade gelatine $(0.6 \%)$, casein
Correspondence: Wael G. Nouh, Department of Pathology, Faculty of Veterinary Medicine, Zagazig University, Zagazig, Egypt.

Tel. +20.106 .8384900 - Fax: +20.552 .283683$

E-mail:wael131269@yahoo.com

Key words: rainbow trout, Flavobacterium psychrophilum, pathology, sensitivity test.

Received for publication: 1 January 2013.

Revision received: 6 March 2013.

Accepted for publication: 27 March 2013.

This work is licensed under a Creative Commons Attribution NonCommercial 3.0 License (CC BYNC 3.0).

CCopyright S.M. Aly et al., 2013

Licensee PAGEPress srl, Italy

Veterinary Science Development 2013; 3:e2 doi:10.4081/vsd.2013.e2

$(0.5 \%)$ and elastin $(0.1 \%)$ is studied on TYES agar plates supplemented with respective substrates. ${ }^{12}$ Reactions are interpreted as positive if a clearing zone surrounds the colonies. The plates are incubated at $15^{\circ} \mathrm{C}$ for up to ten days. Production of catalase is determined by using a fresh bacterial culture and 3\% hydrogen peroxidase and, if necessary, also by microscopic confirmation of the reaction. The cytochrome oxidase reaction is determined by using filter paper soaked with SpotTest $^{\mathrm{TM}}$ 0xidase Reagent (Difco). The reaction has been read within $30 \mathrm{~s}$.

\section{Pathological examination}

The infected fish are examined grossly and tissue specimens (skin, fin, muscle and internal organs) are fixed in 10\% neutral buffered formalin, processed routinely, blocked in paraffin, sectioned at $5 \mu \mathrm{m}$ and stained with hematoxylin and eosin (H\&E). ${ }^{13}$

\section{Electron microscopic examination}

Selected lesions from the liver and kidney are fixed in $6.25 \%$ coccodylate buffer gluteraldehyde followed by $1 \%$ osmium tetraoxide. After dehydration, the specimens are embedded in polyethylene capsules containing the embedding mixture. Ultrathin sections are prepared and stained by uranyl acetate and lead citrate. 14

\section{Antibiotic sensitivity test}

This test is performed by the disc diffusion method using Muller Hinton agar according to Bauer. 15 The antibiotics used are oxytetracycline, trimethoprime, chloramin T, erythromycin, novobiocin and ampicillin. 


\section{Results}

\section{Clinical signs}

The infected rainbow trout have sluggish movement and respiratory distress. Swelling of the head, fin rot and marked skin lesions are evident (Figure 1). Mortality among the infected trout has reached $25 \%$.

\section{Postmortem examination}

Necrotic fin and skin lesions are the most common postmortem lesions. The signs of septicemia (congestion, petechial hemorrhage, marked swelling and necrotic foci) are seen in the internal organs of most infected trout. The necrotic skin lesions may extend deep to the underlying muscles and involve the gill lamellae. During late infection, the fish present dark pigmented skin.

\section{Bacteriological examination}

Bacteriological examination reveals the isolation of Flavobacterium psychrophila. This bacteria is isolated from fish (skin and muscles) and water samples but not obtained from fish feed. It is motile Gram negative bacilli, oxidase positive and does not metabolize carbohydrates but has strong proteolytic activities.

\section{Histopathological findings}

The fin and skin lesions are represented either by superficial to deep epithelial sloughing (erosion to ulceration) and/or by hyperplasia. The surrounding area of the skin showed vacuolar to ballooning degeneration. The dermal tissue showed edema and focal infiltration of melanomacrophages (Figures 2 and 3 ). The underlying muscles of most cases revealed edema, hemorrhage, hyaline degeneration and Zenker's necrosis. Congestion and cellular infiltration were seen in some cases (Figure 4). The internal organs, especially the liver and kidneys, suffered degenerative changes (vacuolar degeneration), circulatory disturbances (congestion and hemorrhage) and focal areas of coagulative necrosis (Figures 5 and 6). The gills revealed alternative sloughing and/or hyperplasia in the primary and secondary lamellae (Figure 7).

\section{Electron microscopic observations}

The hepatocytes of selected hepatic lesions revealed swelling of rough endoplasmic reticulum, aggregation of fat globules, degeneration and shrinkage of mitochondria, marked lysozomal activities and many ribosomes and peroxisomes disbursed within the cytoplasm. The nucleus showed signs of pyknosis with condensation of heterochromatin and/or euchromatin (Figure 8).

The renal epithelium of the same infected cases showed marked swelling and vacuolation of mitochondria and marked lysozomal activities. The nucleus is small in size and revealed disbursed chromatin materials (Figure 9).

\section{Antibiotic sensitivity}

The results of antibiotic sensitivity test on the isolated bacteria showed the efficiency of trimethoprime, chloramin T, oxytetracycline, novobiocin, erythromycin and ampicillin in descending order.

\section{Discussion and Conclusions}

Flavobacterium psychrophilum causes a severe disease in fish, especially in farmed rainbow trout (Oncorhynchus mykiss), all over the world. Over the past few years, in many parts of Europe, rainbow trout fry syndrome and bacterial cold water disease caused by $F$. pschrophilum have become the most serious bacterial fish diseases. ${ }^{9}$ This bacterium is a long slender, Gram negative rod measuring $0.75 \times 1.5-5 \mathrm{~nm} .16$ It can be transmitted horizontally either indirectly through the water column or directly by fish-to-fish contact. Vertical transmission and carrier fish may play a role in the disease transfer.2,3,17-19 The pathogen has been detected also in eels, carp, tench and crucian carp. ${ }^{2}$

The pathogen causes disease at low temperatures $\left(4.4-10^{\circ} \mathrm{C}\right) .{ }^{20}$ The disease may also be systemic, $, 2,3$ but the demonstration of the bacterium from tissues other than the skin and muscles of the caudal peduncle may not be possible. ${ }^{17}$ Similar results are reported in the present study in which pathological alterations are reported in the internal organs that indicated systemic involvement, 10 although the bacterium is only isolated from the skin and muscle lesions. This could be due to the dissemination of the bacterial extracellular products to the general circulation.

Based on the gross lesions, the disease could easily be confused with furunculosis, bacterial kidney disease or columnaris disease caused by $A$. salmonicida, $R$. salmoninarum or F. columnaris, respectively. But impression smears from the skin lesion and/or Gram stain would quickly eliminate differentiate between other diseases based on the size of bacteria and Gram reaction. On the other hand, $F$. columnaris does not usually cause disease at such a low water temperature. The clinical signs and postmortem lesions reported in the infected trout of the present study are similar to those reported by Lumsden et al.,21 Roberts and Bebak.22,23 Ekman and Norrgren experimentally infected rainbow trout, Oncorhynchus mykiss (Walbaum), sea trout, Salmo trutta L., and Atlantic salmon, Salmo salar L., with Flavobacterium psychrophilum in order to evaluate any species that shows different susceptibility to the bacterium. ${ }^{24}$ No significant differences in mortality among the species were recorded. Clinical signs and pathological findings are similar in the three species and in accordance with those of rainbow trout fry syndrome. Nilsen et al. ${ }^{10}$ reported that infection of Atlantic salmon Salmo salar (L.) by Flavobacterium psychrophilum reveals a swollen dark spleen, pale liver, serohemorrhagic ascites and hemorrhage in the abdominal fat and muscle of dead and moribund fish in which $F$. psychrophilum is isolated from the kidney and spleen of diseased fish while muscle biopsy reveals the presence of long filamentous rods in necrotic areas of skeletal muscle.

Histopathologically, the epithelial damage that is reported in the skin and fin could frequently result in a hyperplastic reaction as a protective response, especially at lower temperature. ${ }^{25}$ It has also been suggested that bacterial extracellular products can induce epithelial hyperplasia and activation of melanomacrophages, and similar results are noticed in the skin, fin and gills of infected trout. 4,26

For some reason, bacteria penetrate the epidermis and dermis to the underlying muscles where they proliferate and induce muscular lesions that could facilitate systemic spreading. Similar lesions are reported by Lumsden $e t$ $a l .,{ }^{21}$ and Miwa and Nakayasu. 5 The observed necrotic myositis in some infected cases is an unusual lesion to the classical bacterial cold water disease. ${ }^{27}$ However it could result from reduced temperate phynotypical properties of the causative agent or the ability of the organism to invade systemically. In the present study, the observed pathological changes in the internal organs of the infected trout confirm this hypothesis. Ekman and Norrgren examined rainbow trout infected with Flavobacterium psychrophilum and found more pronounced lesions in the spleen compared with the other species. ${ }^{24}$ Necrosis of renal tubular epithelium and hematopoietic tissue were most prominent in rainbow trout and Atlantic salmon. Intracellular eosinophilic droplets in the kidney tubular epithelium are a prominent finding in rainbow trout and sea trout surviving the infection.

The ultrastructural changes observed in the hepatocytes and in the renal epithelium of the infected rainbow trout in the present study indicate the effect of $F$. psychrophilum on the internal organs directly through the circulation of their extracellular products or indirectly through the hypoxia that resulted from the gill damage or the ionic imbalance, themselves due to the failure of the osmoregulatory mechanisms caused by the skin and gill lesions. The aggregation of fat globules in the hepatocytes could indicate a failure in the oxidative phosphorylation process. The severe lesion in the 
renal epithelial mitochondria could complicate the failure of the osmoregulation due to the skin lesions and lead to a high mortality rate among infected trout. Similar lesions are reported by Rangdale et al. .28

The histopathological and ultrastructural alterations in the infected trout explain the pathogenicity of this microorganism in many organs other than skin and fins, either directly

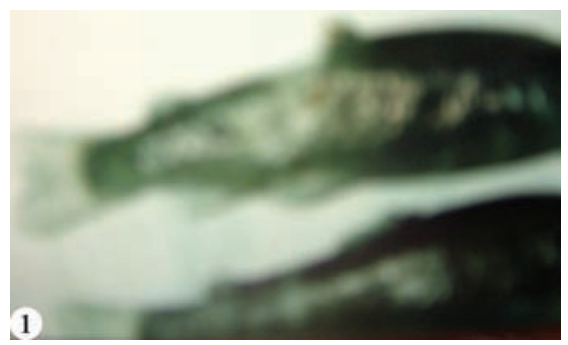

Figure 1. Trout showing fin rot and marked skin lesions.

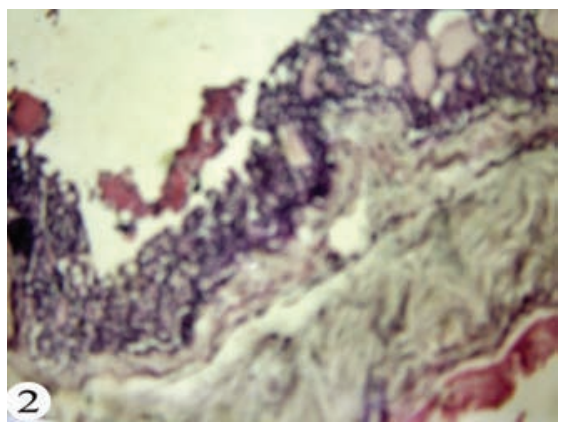

Figure 2. Fin showing vacuolar to ballooning degeneration and dermal edema. Haematoxylin \& Eosin staining, magnification $250 x$

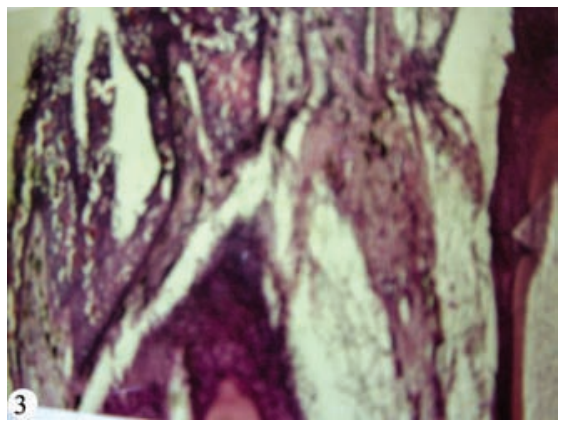

Figure 3. Skin showing epithelial sloughing, ballooning degeneration, dermal edema and focal infiltration of melanomacrophages. Haematoxylin \& Eosin staining, magnification 250x. by these bacterium or its extracellular products or indirectly via the hypoxia and ion imbalance that resulted from skin and gill damage. Although, antimicrobial sensitivity reveals the efficiency of oxytetracycline, this antibiotic is no longer recommended for the treatment of fish on farms. ${ }^{29}$ However, trimethoprime and chloramine $\mathrm{T}$ are more efficient than oxytetracycline with little cytopathic effect, but treat-

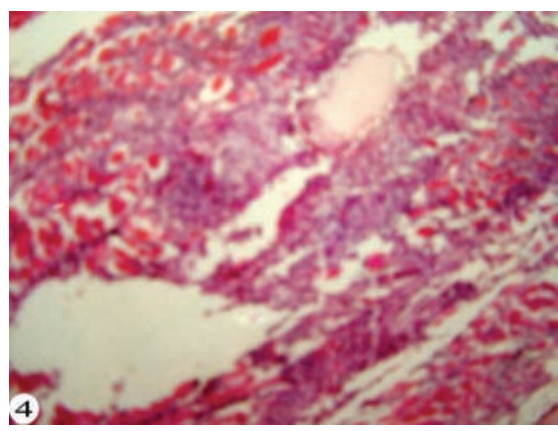

Figure 4. Muscles showing edema, hemorrhage, hyalinization and Zenker's necrosis. Haematoxylin \& Eosin staining, magnification 250x.

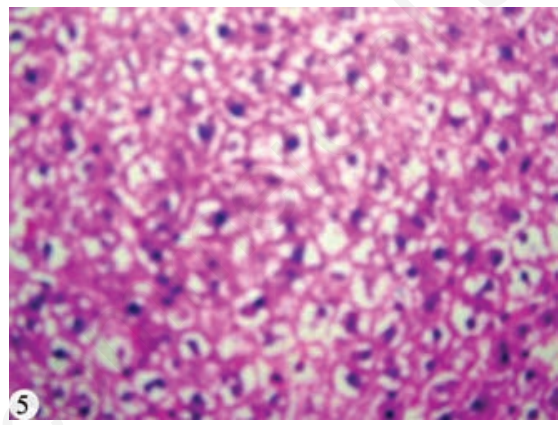

Figure 5. Liver showing vacuolar degeneration and coagulative necrosis. Haematoxylin \& Eosin staining, magnification $250 x$.

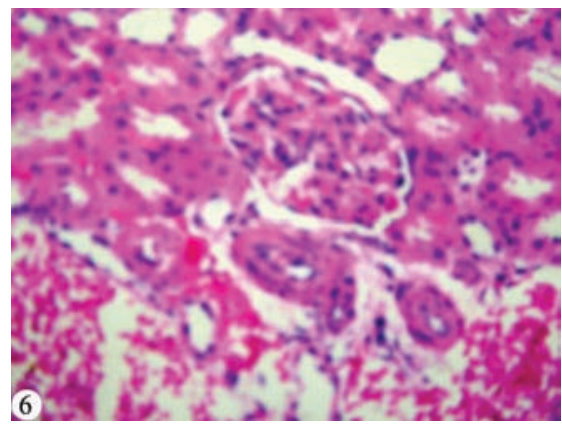

Figure 6. Kidneys showing tubular nephrosis. Haematoxylin \& Eosin staining, magnification $250 x$. ment with these drugs is of little value. Therefore, improvements in water quality along with a possible rise in water temperature and the addition of supportive therapy, such as vitamins and minerals, represent the only treatment of value. Also, increasing the water temperature above the optimum range is the only clear management for prevention of the bacterial cold water disease. ${ }^{2}$

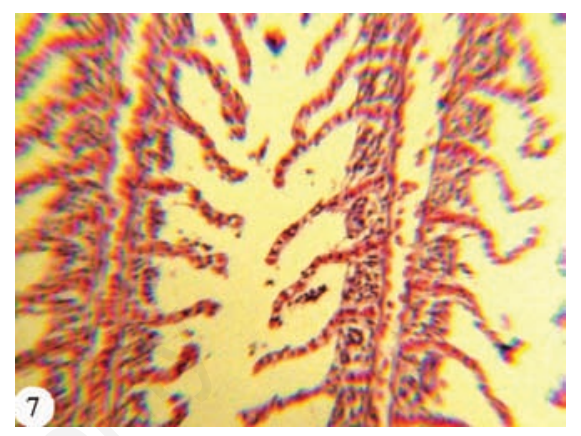

Figure 7. Gills showing sloughing in the primary and secondary lamellae, magnification 100x.

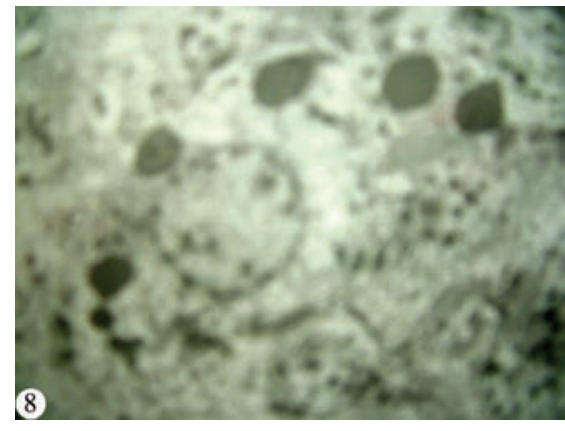

Figure 8. Hepatocytes showing swelling of rough endoplasmic reticulum, aggregation of fat globules, degeneration and shrinkage of mitochondria, marked lysozomal action and condensation of heterochromatin. Uranyl acetate and lead citrate staining, magnification 20,000x.

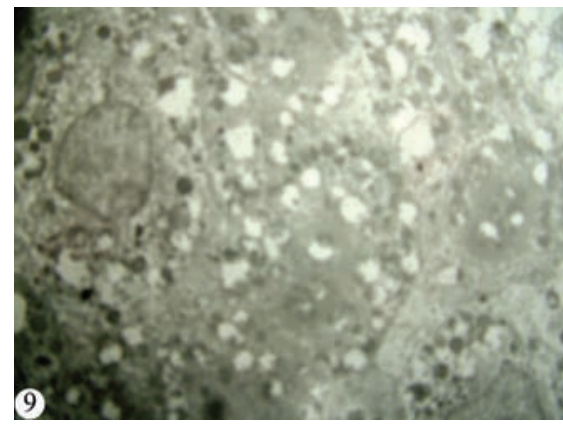

Figure 9. Renal epithelium showing marked swelling and vacuolation of mitochondria and marked lysozomal action. Uranyl acetate and lead citrate staining, magnification 20,000x. 
Although this disease can be treated with antimicrobial drugs or chemical bath treatments, these are not generally used in the environment due to the harmful and heavy impact on the ecosystem. Production of a vaccine against $F$. psychrophilum is recommended. Vigorous egg disinfection should be administered and fish resistance to the infection should be increased by the addition of immunostimulants or probiotics, especially in endemic areas. Strict hygiene and quarantine measures should be applied to prevent this pathogen entering farms or countries that are, for the moment, pathogen free. Further studies are required for a more detailed investigation into this bacterium, its extracellular products, epidemiology and the pathogenesis of this disease.

\section{References}

1. Austin B, Austin D. Bacterial fish pathogens. Diseases in farmed and wild fish. 2nd ed. London: Ellis Harwood; 1999. p 432.

2. Plumb JA. Health maintenance and principal microbial diseases of cultured fishes. Oxford: John Wiley \& Sons; 1999.

3. Woo PTK, Bruno DW. Fish diseases and disorders. Vol. 3. Viral, bacterial and fungal infections. Available from: http://bookshop.cabi.org/Uploads/Books/PDF/9780851 991948/9780851991948.pdf.

4. Aoki M, Kondo M, Kawai K, Oshima S. Experimental bath infection with Flavobacterium psychrophilum, inducing typical signs of rainbow trout Oncorhynchus mykiss fry syndrome. Dis Aquat Organ 2005;67:73-9.

5. Miwa S, Nakayasu C. Pathogenesis of experimentally induced bacterial cold water disease in ayu Plecoglossus altivelis. Dis Aquat Organ 2005;67:93-104.

6. Holt RA, Rohovec JS, Fryer JL. Bacterial cold water disease. In: Inglis V, Roberts RJ, Bromage NR, eds. Bacterial diseases of fish. Oxford: Blackwell Scientific Publications; 1993. pp 3-23.

7. Lorenzen E, Karas N. Detection of Flexibacter psychrophilus by immunofluorescence in fish suffering from fry mortality syndrome: a raid diagnostic method.
Dis Aquat Organ 1992;13:231-4.

8. Lorenzen E. Studies on Flexibacter psychrophilus in relation to rainbow trout fry syndrome (RTES). PhD Diss., University of Copenhagen, Denmark; 1994.

9. Nematollahi A, Decostere A, Pasmans F, Haesebrouck F. Flavobacterium psychrophilum infections in salmonid fish. $\mathrm{J}$ Fish Dis 2003;26:563-74.

10. Nilsen H, Johansen R, Colquhoun DJ, et al. Flavobacterium psychrophilum associated with septicaemia and necrotic myositis in Atlantic salmon Salmo salar: a case report. Dis Aquat Organ 2003;97:37-46.

11. Madetoja J, Hänninen ML, Hirvelä-Koski V, et al. Phenotypic and genotypic characterization of Flavobacterium psychrophilum from Finnish fish farms. J Fish Dis 2001;24:469-79.

12. Madsen L, Dalsgaard I. Characterization of Flavobacterium psychrophilum; comparison of proteolytic activity and virulence of strains isolated from rainbow trout (Oncorhynchus mykiss). In: Barnes AC, Davidson GA, Hiney MP, McIntosh D, eds. Methodology in fish diseases research. Aberdeen: Fisheries Research Services; 1998. pp 45-52.

13. Bancroft TD, Stevens A, Turner DR. Theory and practice of histological technique. 4th ed. London: Churchill Livingston; 1996.

14. Weakly B. A beginner's handbook in biological transmission electron microscopy. London: Churchill Livingston; 1981.

15. Bauer A. Antibiotic susceptibility testing by a standardized single disc method. Am J Clin Pathol 1966;45:493-6.

16. Pacha R, Ordal E. Myxobacteria diseases of salmonids: prevention and treatment. In: Snieszko S. A symposium on diseases of fish and shellfishes. American Fisheries Society; 1970. pp. 243-257.

17. Wood W. Diseases of Pacific salmon: their preventition and treatment. State of Washington, Dept. of Fisheries, Hatchery Division; 1974. p 82.

18. Brown LL, Cox WT, Levine RP. Evidence that the causal agent of bacterial coldwater disease Flavobacterium psychrophilum is transmitted within salmonid eggs. Dis Aquat Org 1997;29:2138.

19. Ekman E, Akerman G, Balk L, Norrgren L. Nanoinjection as a tool to mimic vertical transmission of Flavobacterium psychrophilum in rainbow trout Oncorhynchus mykiss. Dis Aquat Org 2003;55:93-9.

20. Shotts EB, Starliper CE. Flavobacterial diseases, columnaris. disease, cold-water disease and bacterial gill disease. In: Woo PTK, Bruno DW, eds. Fish diseases and disorders. Vol 3. Viral, bacterial and fungal infections. New York; CABI Publishing: 1999. pp 559-576.

21. Lumsden J, Ostland V, Fergnson H. Necrotic myositis in cage cultured rainbow trout Oncorhynchus mykiss (Walbaum) caused by Flexibacter psychrophilus. J Fish Dis 1996;19:113-9.

22. Roberts RJ. Fish Pathology. 3rd ed. London: WB Sauders; 2001.

23. Bebak JA, Welch TJ, Starliper CE, et al. Improved husbandry to control an outbreak of rainbow trout fry syndrome caused by infection with Flavobacterium psychrophilum. J Am Vet Med Assoc 2007; 231114-6.

24. Ekman E, Norrgren L. Pathology and immunohistochemistry in three species of salmonids after experimental infection with Flavobacterium psychrophilum. J Fish Dis 2003;26:529-38.

25. Roberts RJ, Bullock A. The dermatology of marine teleost fish II. Dermatopathology of the integument. Oceanogr Mar Biol Ann Rev 1197;614:227-46.

26. Nematollahi A, Decostere A, Pasmans F, et al. Adhesion of high and low virulence Flavobacterium psychrophilum strains to isolated gill arches of rainbow trout Oncorhynchus mykiss. Dis Aquat Org 2003;55:101-7.

27. Holt R, Amandi A, Fryer J. Relation of water temperature to bacterial cold water disease in coho salmon, Chinook salmon and rainbow trout. J Aquat Anim Health 1989;1:97-101.

28. Rangdale RE, Richards RH, Alderman DJ. Histopathological and electron microscopical observations on rainbow trout fry syndrome. Vet Rec 1999;144:251-4.

29. Sundell K, Wiklund T. Effect of biofilm formation on antimicrobial tolerance of Flavobacterium psychrophilum. J Fish Dis 2011;34:373-83. 